\title{
Studies on arterial flow patterns - instantaneous velocity spectrums and their phasic changes - with directional ultrasonic Doppler technique ${ }^{1}$
}

\author{
Yasuharu Nimura, Hirohide Matsuo, Tohru Hayashi, Akira Kitabatake, Shigeki Mochizuki, \\ Hiroshi Sakakibara, Kanemasu Kato, and Hiroshi Abe \\ From the First Department of Medicine, Osaka University Medical School; The Central Laboratory for Clin- \\ ical Investigation, Osaka University Hospital; and The Institute of Scientific and Industrial Research, Osaka \\ University, Osaka, fapan
}

Flow velocity spectra of main arteries in 24 healthy adult subjects and 21 healthy aged subjects were transcutaneously studied using the directional ultrasonic Doppler technique.

I) The instantaneous flow velocity spectrum is continuous throughout a pulse cycle, and intensified near the instantaneous maximum velocity, especially in the early part of a pulse cycle.

2) No reverse flow phase is observed in the common carotid artery except for a small momentary reverse component. A reverse flow phase is always exhibited in the femoral artery and in many occasions in the other main arteries; it follows the systolic forward flow phase. After the reverse flow phase the diastolic forward flow phase appears. In some subjects a second reverse flow phase and third forward flow phase are successively observed.

3) The arterial blood flow almost looks like a propagation of a damped longitudinal oscillation.

4) At the time of conversion between the forward flow phase and the reverse flow phase, both forward and reverse components simultaneously coexist in a cross-section of the vessel.

5) The arterial flow pattern is easily changeable in the arteries of the extremities, especially in the brachial artery. Such an easy changeability is the essential feature of the arterial blood flow.

6) The propagation velocity of the flow velocity wave is more rapid in elderly subjects than in other adult subjects. The reverse flow phase of the arterial flow pattern in the extremities is more often observed in elderly subjects than in adult subjects. In the common carotid artery of elderly subjects the peak velocity is reduced so that the systolic rapid forward phase looks like a plateau.

Studies on the mode of flow in the blood vessels should give us much information on the condition of the cardiovascular system. The ultrasonic Doppler technique offers a useful transcutaneous approach to this study. The technique was originally proposed by Satomura, Matsubara, and Yoshioka (1956) for the physical measurement of minor vibrations. It was also revealed that Doppler beats occurred from the blood flow in the blood vessels (Satomura, 1959; Satomura and Kaneko, 1960). One of the present authors and others (Kato et al., I962) showed that Doppler beats due to the blood

Received 26 November 1973.

${ }^{1}$ This study was supported in part by the Grant in Aid for Developmental Scientific Research of the Ministry of Japan. flow were caused by the back scattering of the ultrasound from the blood corpuscles in the flow. This technique has been clinically applied to the blood vessels by Kaneko and his associates (Kaneko et al., 196r ; Kaneko, Shiraishi, and Omizo, 1968). Franklin, Schlegel, and Rushmer (I96I), Rushmer, Baker, and Stegall (1966), and Reid, Sigelman, and Nasser (1969) have also developed Doppler flowmeters. This technique has come to be widely used in the clinical field (Miyazaki, 1965; Strandness, McCutcheon, and Rushmer, 1966; Strandness et al., 1967; Benchimol et al., 1968; Yao, Hobbs, and Irvine, 1968; Evans and Cockett, 1969; Balas, Segditsas, and Koutsopoulos, 1970; Benchimol, Barreto, and Teng Wei Tio, 1970; Joyner, Harrison, and Gruber, 1971; Benchimol and Desser, 1972). 
Satomura's Doppler technique could reveal the flow velocity; that is, the magnitude of velocity, but not the direction. Recently, Kato and Izumi (1966, I967), Kato, Kakusho, and Izumi (I968), McLeod (1967), Light (1971), Cross and Light (197I), and Pourcelot (I97I) independently proposed their modifications of the Doppler technique for the detection of the direction of the blood flow as well as the magnitude of velocity. A number of papers, by Strandness et al. (1969), Benchimol, Desser, and Gartlan (1972), Kalmanson et al. (1972), Cross and Light (1971), Light and Cross (1972), and so forth, have been published on the clinical application of the directional Doppler technique.

A frequency discriminator, a zero-crossing counter, and a sound spectrograph have been used for the display of the Doppler output from the blood flow (Kato, 1966). Of the above-mentioned methods, the sound spectrogram provides unique information concerning the blood flow, though its use is somewhat troublesome (Kaneko et al., 1965, 1970; Light, 1970). In the present study an attempt was made to examine the mode of the blood flow, i.e. the velocity spectrum of the blood flow and its phasic changes, in the main arteries in healthy subjects with the frequency shift method proposed by Kato et al. (1968) and Kato and Izumi (1966, 1967), using a transcutaneous approach.

\section{Subjects and methods}

Forty-five healthy subjects were examined: 24 of them ranged from 22 to 38 years, of whom 21 were men and 3 were women; the 21 ranged from 61 to 83 years, of whom Io were men and II were women. They were shown to be free from cardiovascular disease by medical history, physical examination, and the electrocardiogram at rest.

The studies conducted on the subjects concerned the characteristic features of the blood flow in the main arteries with particular respect to any age differences.

I) Frequency shift method of ultrasonic Doppler technique for detection of direction of motion

The principle of the non-directional method of the Doppler technique is as follows (Satomura et al., I956; Satomura, 1957):

$$
\mathrm{f}_{\mathrm{d}}=\frac{2 \mathrm{v} \cos \theta}{\mathrm{c}} \mathrm{f}_{0}
$$

Here $\mathrm{v}$ represents the velocity of a target, $\theta$ is the angle between the direction of the motion and of the ultrasonic beam, $c$ is the sound velocity, $f_{0}$ is the frequency of the transmitter wave, and $f_{d}$ is the Doppler shift frequency. The Doppler shift frequency is proportional to the velocity component of the target in the direction of the ultrasonic beam.
The Doppler technique was so modified that it might detect not only the magnitude of velocity of the target, but also the direction of velocity (Kato and Izumi, 1966, 1967; Kato et al., 1968). In this case the reflected wave of the frequency $f_{0}+f_{d}$ was led to a detector with a local oscillation of the frequency $f_{0}+f_{L}$, so that the frequency of the beat reads $f_{L}-f_{d}$

$$
f_{L}-f_{d}=f_{L}-\frac{2 v \cos \theta}{c} f_{0} \text {. }
$$

If $f_{L}$ was properly set to be larger than $\left|f_{d}\right|$, the motion towards the transducer, for which $f_{d}$ is positive, was represented by a frequency lower then $f_{L}$, and the motion away from the transducer, for which $f_{d}$ is negative, was represented by a frequency higher than $f_{\mathrm{L}}$. Thus, this modification of the Doppler technique could detect the direction of velocity of the target as well as the magnitude of velocity.

\section{2) Equipment and manipulation}

The equipment used was constructed respectively by Nippon Electric Co. and Hitachi Medico Co., the construction being supervised by Kato. The frequency used was $5 \mathrm{MHz}$, and the frequency of the local oscillation was $5.004 \mathrm{MHz}$ or $5.005 \mathrm{MHz}$. The transducer made of barium titanate, $5 \mathrm{~mm}, 7 \mathrm{~mm}$, or $10 \mathrm{~mm}$ in diameter, was divided into two parts, for transmission and reception, respectively.

A sound spectrograph, made by Rion Co., was used for the display of the Doppler output and a loud-speaker was used as a monitor for listening to the Doppler output. In a spectrogram the level of $f_{L}$ was a tenative baseline for the display of the direction of motion (Fig. 2). The density of the write-out is related to the output voltage, which was proportional to the square root of the number of blood corpuscles per unit volume of the blood (Kato et al., 1962).

The examinees were placed in a supine position at room temperature $20^{\circ}-30^{\circ} \mathrm{C}$. The examination was begun after a ro-minute rest. The examiner confirmed the pathway of the artery with his finger-tips; then the ultrasonic beam was transmitted proximally along the vessel at an angle of $60^{\circ}$ from the skin. If the vessel was parallel with the skin, I KHz corresponds to $300 \mathrm{~mm} /$ sec of the velocity of the target.

After a little training, it was easy to distinguish the arterial Doppler beat from the venous one by monitoring with the loud speaker. It was also easy to distinguish the two on the spectrogram.

The common carotid artery was examined in the lower half of the neck, the subclavian artery at the infraclavicular fossa, the brachial artery at the flexor side of the elbow joint, the radial artery just at the proximal region of the wrist joint, the femoral artery in the inguinal region, and the dorsalis pedis artery in the middle of the instep.

\section{Results}

The features examined were the general configuration of the spectrographic pattern, the instantaneous maximum velocity, the peak velocity, the 


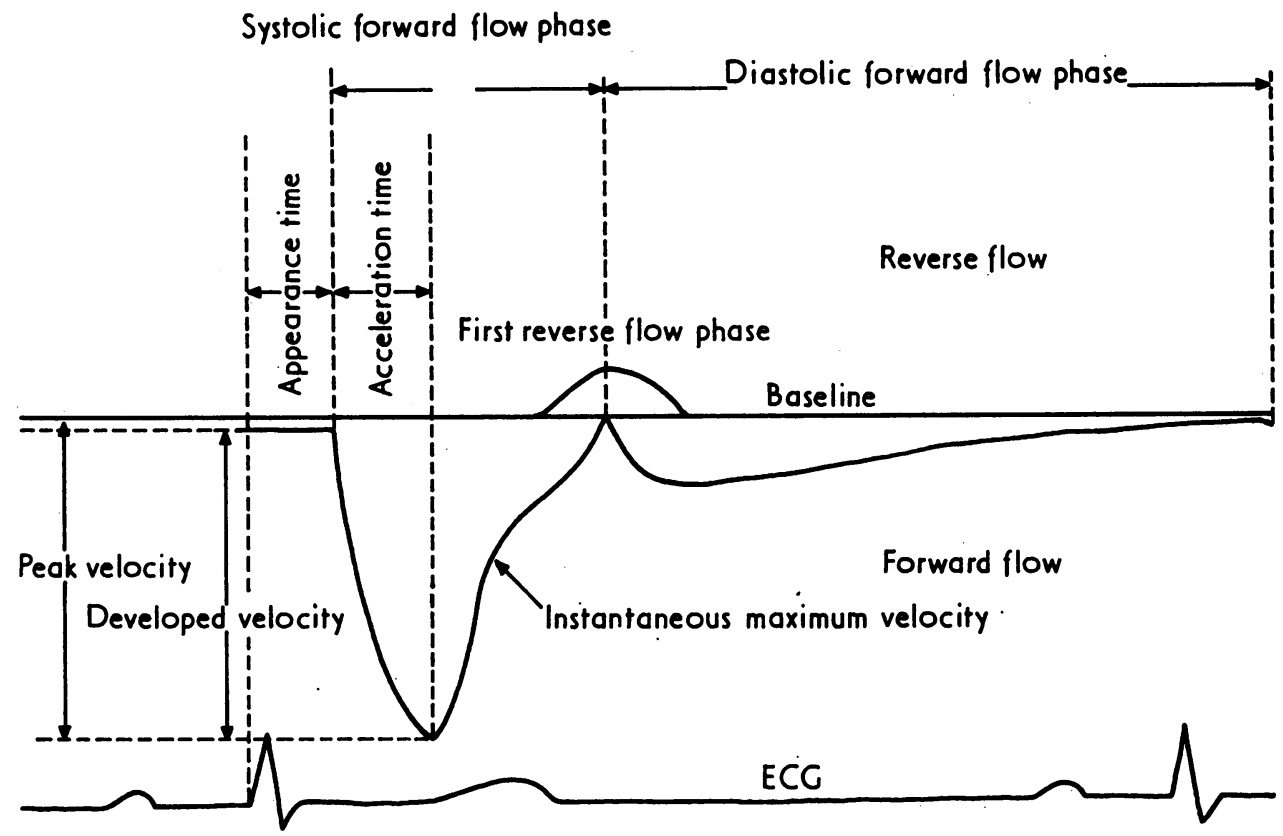

FIG. I The nomenclature used in the present study for the arterial blood flow pattern. Systolic forward flow phase: time interval in which the flow velocity is high because of cardiac systole; first reverse flow phase: time interval after the systolic forward flow phase and showing a distal to proximal flow; diastolic forward flow phase: time interval after the systolic forward flow phase or the first reverse flow phase and corresponding to cardiac diastole. The flow velocity is low in this phase; instantaneous maximum velocity: maximum velocity in a cross-section of the vessel in any instant in a pulse cycle; peak velocity: the highest velocity in a pulse cycle; developed velocity: the highest velocity - end-diastolic flow velocity, i.e. velocity increment due to cardiac systole; appearance time: time interval from the beginning of the $Q R S$ complex of the electrocardiogram to the beginning of the systolic forward flow phase; acceleration time: time interval from the beginning of the systolic forward flow phase to the instant of peak velocity.

appearance time, the acceleration time, and the acceleration itself (Fig. I).

\section{I) Common carotid artery}

The typical configuration of the spectrographic pattern of the flow of the common carotid artery was composed of the systolic forward flow phase, which corresponded to cardiac systole, and the diastolic slow forward flow phase, which corresponded to cardiac diastole (Kaneko et al., 1970) (Fig. 2). The systolic forward flow phase exhibited two peaks. A small valley was noted between the systolic forward flow phase and the diastolic forward flow phase, and this amounted to a small momentary reverse component in 13 subjects (Fig. 2 and Table). The dicrotic notch on the carotid pulse tracing coincided with this valley. In some subjects an irregular reverse component was observed throughout the systolic and diastolic phases (Fig. 3). This phenomenon was left unexplained and the question of whether it was due to vortex motion in the arterial flow or to a contamination of the Doppler output from the venous flow remains to be studied.

The Doppler output seemed more intense on the tracing near the instantaneous maximum velocity on the spectrogram during the acceleration time and was homogeneous in the whole frequency range from zero to the instantaneous maximum velocity after the peak of the systolic forward flow phase. This was also observed in all the other arteries examined. The peak velocity in the common carotid artery was, in general, slower in the elderly. In the systolic forward flow phase of the aged the first peak was near the second peak in height so that they were generally plateau-like (Fig. 4). 
TABLE Peak velocity, appearance time, acceleration, appearance of reverse flow phase and peak reverse velocity in each artery in adults and elderly. Here, acceleration is determined by dividing developed velocity by acceleration time

\begin{tabular}{|c|c|c|c|c|c|c|}
\hline & \multirow[b]{2}{*}{ No. } & \multirow[b]{2}{*}{$\begin{array}{l}\text { Max. velocity } \\
(\mathrm{cm} / \mathrm{sec}) \\
\text { average }(S D)\end{array}$} & \multirow[b]{2}{*}{$\begin{array}{l}\text { Appearance time } \\
(\mathrm{sec}) \\
\text { average }(S D)\end{array}$} & \multirow[b]{2}{*}{$\begin{array}{l}\text { Acceleration } \\
\mathrm{cm} / \mathrm{sec}^{2} \\
\text { average }(S D)\end{array}$} & \multicolumn{2}{|c|}{ Reverse flow } \\
\hline & & & & & No. & $\begin{array}{l}\text { Max. velocity } \\
(\mathrm{cm} / \mathrm{sec}) \\
\text { average }(S D)\end{array}$ \\
\hline \multicolumn{7}{|c|}{ Common carotid artery } \\
\hline adult subjects & 23 & II3.I $(20.04)$ & $0.11(0.018)$ & $1438(5 \mathrm{I} 5 \cdot \mathrm{I})$ & 4 & $9 \cdot 5$ \\
\hline elderly subjects & $2 I$ & $\begin{array}{l}70.1(17.52) \\
\mathrm{P}<0.01\end{array}$ & $\begin{array}{l}0.11(0.018) \\
\text { NS }\end{array}$ & $\begin{array}{l}1044(301 \cdot 5) \\
P<0.01\end{array}$ & 9 & $I I \cdot O(7 \cdot 28)$ \\
\hline \multicolumn{7}{|l|}{ Brachial artery } \\
\hline adult subjects & 22 & $92 \cdot 1(18 \cdot 75)$ & $0.18(0.018)$ & $1072(225 \cdot 9)$ & 8 & $17 \cdot 9(4 \cdot 79)$ \\
\hline elderly subjects & 21 & $\begin{array}{l}78.5(17.07) \\
0.01<P<0.1\end{array}$ & $\begin{array}{l}0.16(0.022) \\
P<0.01\end{array}$ & $\begin{array}{l}\text { I077 }(186 \cdot 2) \\
\text { NS }\end{array}$ & 15 & $14 \cdot 3(5 \cdot 03)$ \\
\hline \multicolumn{7}{|l|}{ Radial artery } \\
\hline adult subjects & I5 & $75 \cdot 3$ (16.99) & $0.21(0.013)$ & $915(203.5)$ & 2 & 13.3 \\
\hline elderly subjects & $2 I$ & $\begin{array}{l}64.2(16.33) \\
P<0.01\end{array}$ & $\begin{array}{l}0.17(0.017) \\
P<0.01\end{array}$ & $\begin{array}{l}1130(255.8) \\
0.01<P<0.1\end{array}$ & 7 & $10 \cdot 2(2 \cdot 25)$ \\
\hline \multicolumn{7}{|l|}{ Femoral artery } \\
\hline adult subjects & 18 & $88.2(10.52)$ & $0.21(0.019)$ & $824(157 \cdot 7)$ & 18 & $3 I \cdot 6(6 \cdot 80)$ \\
\hline elderly subjects & 18 & $\begin{array}{l}\text { IOI.8 }(29.1 \mathrm{I}) \\
0.01<\mathrm{P}<0.1\end{array}$ & $\begin{array}{l}0.16(0.019) \\
P<0.01\end{array}$ & $\begin{array}{l}\text { I043 (288.2) } \\
\mathrm{P}<0.01\end{array}$ & 18 & $\begin{array}{l}25.4(9.56) \\
0.01<P<0.1\end{array}$ \\
\hline
\end{tabular}

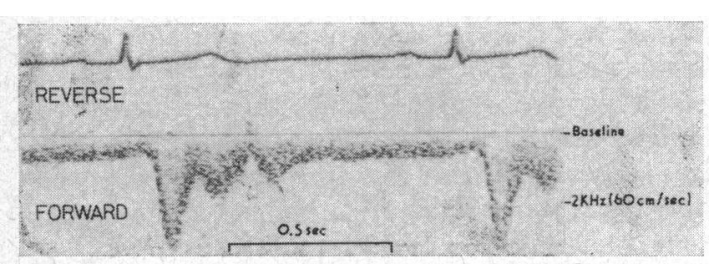

FIG. 2 An example of the flow pattern of the common carotid artery in a healthy subject. It is composed of the systolic and diastolic forward flow phases. The systolic forward flow phase exhibits two peaks. A small momentary reverse component is noted between the above-mentioned two phases (a 29-year-old man).

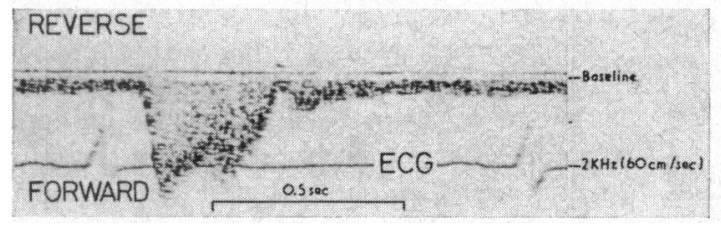

FIG. 4 An example of the flow pattern of the common carotid artery in the aged. In the systolic forward flow phase peak velocity is so reduced that the height of the first peak is almost the same as that of the second peak. The systolic forward flow phase shows a plateaulike pattern (a 78-year-old woman).

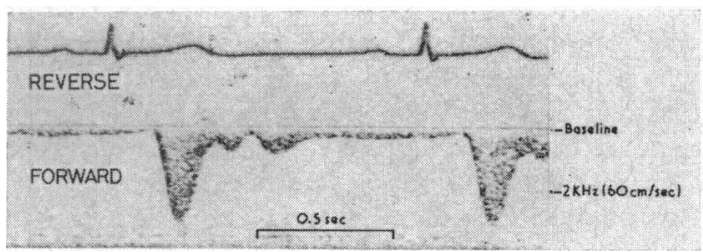
common carotid artery. It is left unexplained whether an irregular reverse component throughout the systolic and diastolic forward flow phases is due to vortex motion at a branching site or to a contamination of the Doppler output from the venous flow. This remains to be studied (a 27-year-old man).
FIG. 3 Another example of the flow pattern of the

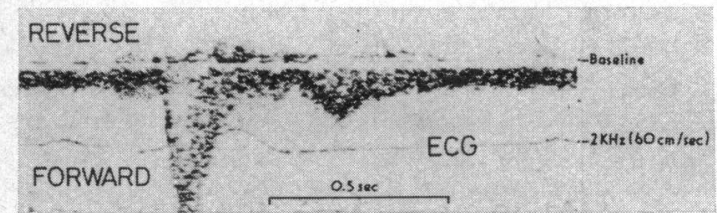

FIG. 5 An example of the flow pattern of the brachial artery. In the systolic forward flow phase the height of the second peak becomes so low that the flow pattern in this phase seems almost one-peaked; no reverse flow phase appears (a 29-year-old man). 


\section{2) Subclavian artery}

The pathway of the subclavian artery was not easily identified, making it difficult to get the desired angle between the ultrasonic beam and the vessel. Hence, there was noted a large distribution range of the results obtained from examination of this artery.

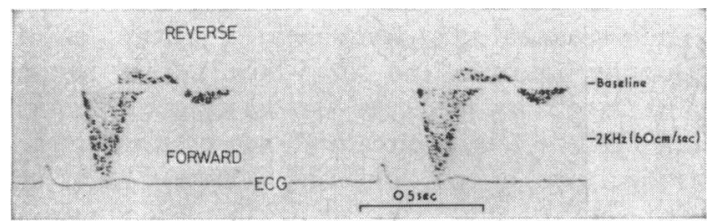

FIG. 6 Another example of the flow pattern of the brachial artery. A reverse flow phase is observed followed by the diastolic forward flow phase. The blood flow is stopped in the last stage of a pulse cycle (a 29year-old man).

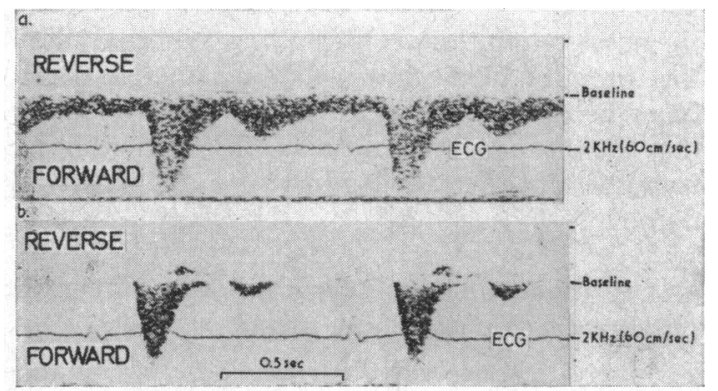

FIG. 7 Change of the flow pattern of the brachial artery due to a piece of ice put on the palm. a) Before the test; b) after the test: the flow velocity in the systolic forward flow phase is reduced, followed by the first reverse phase; the blood flow disappeared in diastole, except for the diastolic forward flow phase lasting only a short time (a 29-year-old man).

\section{3) Brachial artery}

In the systolic forward flow phase of the brachial artery a peak corresponding to the second peak in the common carotid artery was so low that the configuration looked single-peaked, and the duration of the main peak was shorter than the ejection time of the heart. Such a trend was commonly observed in all the main peripheral arteries mentioned in this and the following sections (Fig. 5).

Various kinds of configurations in the flow pattern of this artery were noted. In some subjects the blood flow was unidirectional throughout a pulse cycle (Fig. 5). Other subjects exhibited the slow reverse flow phase after the systolic forward flow phase, followed again by the slower diastolic forward flow phase, and the blood flow almost stopped at the late stage of a pulse cycle (Fig. 6). In a third and intermediate pattern the blood flow almost stopped, but was not reversed, between the systolic forward flow phase and the diastolic forward flow phase.

The reverse flow phase was more often observed in the elderly under physiologically stable conditions at rest (Table).

The blood flow pattern in the brachial artery was readily changeable so that it easily shifted from the pattern without to the pattern with the reverse flow phase by an external cause, e.g. by putting a piece of ice on the palm (Fig. 7). Removal of the piece of ice resulted in the return to the former blood flow pattern. In some subjects the change was easily caused even by being addressed by the examiner. In general, transition of the flow pattern from one kind to another quickly occurred within an interval of several pulse cycles (Fig. 8).

\section{4) Radial artery}

The peak velocity was slower in the radial artery than in the brachial artery (Table).

The flow pattern of the radial artery was not so labile as that of the brachial artery (Table).

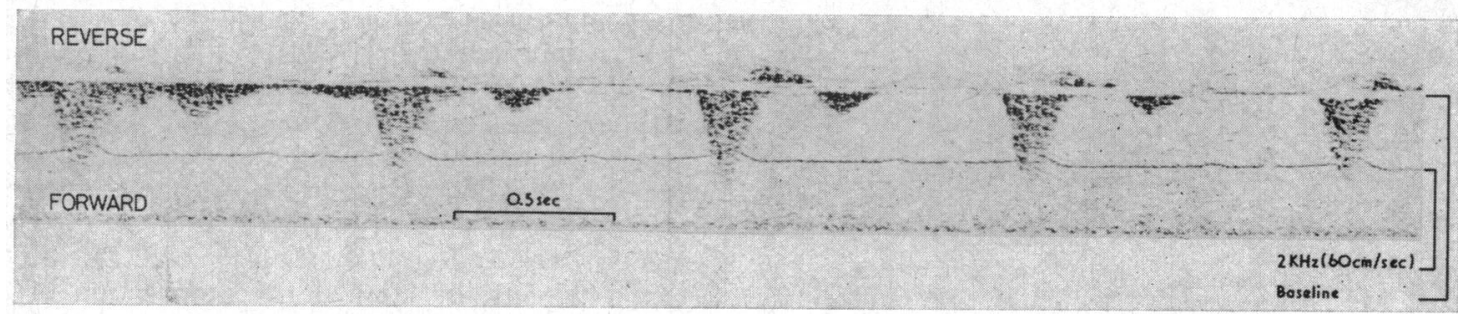

FIG. 8 Rapid change in the flow pattern of the brachial artery. When the examinee was addressed by the examiner, the flow pattern changed within an interval of several pulse cycles (a 25-year-old woman). 


\section{5) Femoral artery}

The intensity of the Doppler output was much higher in the femoral artery than in the other arteries in the extremities. In all the subjects examined, the slow reverse flow phase occurred after the systolic forward flow phase (Table). Then, there again occurred the slower diastolic forward flow phase (Fig. 9). In some subjects, there were further observed the second reverse flow phase followed by the third forward flow phase, with a reduction in the magnitude of their velocity.

It was discovered that a forward flow component and a reverse component coexist in the same crosssection of the artery at the time of conversion between the forward flow phase and the reverse flow phase (Fig. 9). This was also noted in the other arteries, but was most pronounced in the femoral artery.

\section{6) Dorsalis pedis artery}

The intensity of the Doppler output was much lower in the dorsalis pedis artery than in the other arteries. In this artery, the flow velocity was usually slow. The reverse flow phase was observed in many cases.

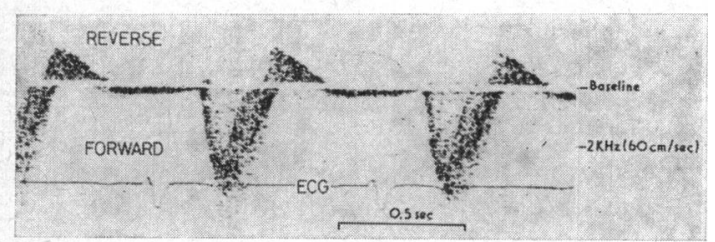

FIG. 9 An example of the flow pattern of the femoral artery. The reverse flow phase is noted after the systolic forward flow phase. Then, there again occurs the diastolic forward flow phase (a 28-year-old man).

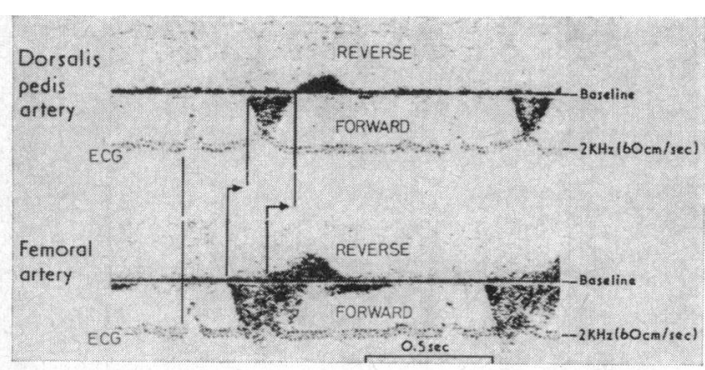

FIG. Io Temporal relation between the flow patterns of the femoral artery and of the dorsalis pedis artery. The reverse flow phase is propagated from the proximal to the distal artery after the preceding forward flow phase (a 21-year-old man).
Propagation of the reverse flow phase was examined in reference to the femoral artery and the dorsalis pedis artery. It was found that the reverse flow phase was propagated from proximal to distal after the preceding forward flow phase (Fig. IO).

\section{Discussion}

\section{I) Velocity spectrum of blood flow}

The instantaneous frequency spectrum of the Doppler output of the blood flow, i.e. the instantaneous velocity spectrum, was continuous throughout a pulse cycle, as already shown by Kaneko et al. (1965, 1970), Cross and Light (I971), Light and Cross (1972), and Light (1970). The velocity profile at a cross-section of a steady laminar flow of Newtonian fluid is known to be parabolic, so it would make the velocity spectrum homogeneous from zero to the maximum velocity at any instant. However, the instantaneous velocity spectrum of the artery obtained in the present study was not necessarily homogeneous, but looked more intense near the instantaneous maximum velocity especially during the acceleration time. This finding indicated that at that time the blood flow is driven rather uniformly in a whole section, i.e. with a flat velocity profile, so that the blood flow would be considerably different from that of the steady laminar flow of a Newtonian fluid.

\section{2) Undulatory character of velocity pulse and} presence of reverse flow phase

Peripheral arteries revealed, as a rule, an undulatory flow even during the period corresponding to diastole of the heart; reverse components were also often exhibited. Such findings have already been reported by Strandness et al. (1969) and Kaneko et al. (1970). The forward flow phase and the reverse flow phase repeatedly appeared one after the other, with the amplitude gradually reducing (Fig. 6). The reverse flow phase appeared more often in the middle part of the artery than in the more distal part, as shown in the cases of the brachial artery and the radial artery (Table). This seemed to result mainly from the elasticity of the vessel wall of the middle part of the artery, in association with peripheral resistance, in terms of the Windkessel theory. Interestingly enough, the duration of the systolic forward flow phase in the peripheral arteries proved to be much shorter than that of the cardiac ejection period. Recently, Anliker and Rockwell (I97I) theoretically studied the propagation of a pressure wave in a tapered elastic tube with an assumption of one-dimensional motion of the incompressible fluid. Their findings showed that as the pulse wave is propagated, the wave front 
steepens considerably with distance. The abovementioned finding in the present study may correspond to those authors' theoretical consideration.

3) Propagation of velocity pulse waves and coexistence of forward and reverse components

In the arteries the reverse flow phase was propagated from proximal to distal, following the preceding forward flow phase (Fig. IO). This finding suggested that the reverse flow phase did not result from, 'a rebound from the periphery,' but largely from the nature of the vessel wall, i.e. elasticity, as mentioned above. The time sequence of flow velocity at a certain site of the middle-sized artery was like a damped oscillation (Fig. 6). Thus, the arterial flow can be regarded as propagation of the longitudinal wave of such a damped oscillation from proximal to distal in the blood column, undergoing some modification of the configuration and amplitude with distance.

It was revealed that the forward and reverse components transiently coexisted in a cross-section of the vessel at the time of conversion between forward and reverse (Fig. 9). Such a phenomenon was also noted by Strandness et al. (1969) who used the phase shift method of the Doppler technique. Previously Womersley (1955) and Hale, McDonald, and Womersley (1955) studied the fluid dynamics of a pulstile flow of viscous liquid in a solid tube. They theoretically showed that at the time of pulstile change of the direction of flow the circumferential flow changes its direction earlier than the central flow, while the latter remains a forward direction, so that there transiently coexist the forward flow and the reverse flow in a cross-section of the tube. Sakamoto, Saito, and Nakayama (1966) performed a similar study using an elastic tube with a similar result. The transient coexistence of the forward flow and the reverse flow, revealed in the present study, was assumed to correspond to the results of the above-mentioned theoretical consideration, though only the velocity spectrum was considered in the present study, leaving velocity distribution undetermined.

\section{4) Variability of flow pattern in arteries}

The blood flow pattern was easily changed even at a definite site of the artery, being sensitive to and responding to external conditions (Fig. 7). Kaneko et al. (I96I) previously reported that there is a close relation between the blood flow pattern and room temperature. This variability was also reported by Kobayashi (197I). The response was immediate, occurring within several pulse periods (Fig. 8). The easy variability of the blood flow pattern is thus assumed to be related to vasomotor activity. It has been reported that lumbar sympathectomy resulted in an increase of effective flow and the disappearance of reverse flow in the femoral artery (Lee, Castillo, and Madden, 1970). Therefore, it is considered that the immediate appearance or augmentation of the reverse flow phase in the artery due to external causes is related to the increase of peripheral resistance due to vasoconstriction.

This easy variability is considered to be one of the essential features of the blood flow of peripheral arteries. It was obvious that the change was not random, but followed certain conditions.

\section{5) Difference of blood flow pattern depending upon age}

There was a notable difference in the arterial flow pattern with respect to age.

The appearance time of the arterial flow pattern was shorter in the aged than in adults (Mizuno, 1969) (Table). Such a difference has been noted even in a conventional pulse tracing. It had been interpreted as resulting from the acceleration of the propagation velocity of pulse wave due to sclerotic changes of the blood vessels.

In the present study, the conditions of examination seemed alike both for the elderly and the other subjects. So, it was very significant that the reverse flow phase was more frequently detected in the elderly (Table). Considering the discussion in section (2) concerning the reverse flow phase, the frequent appearance of the reverse flow phase in the elderly was interpreted to suggest a higher peripheral resistance.

Another remarkable difference was noted between the elderly and the other subjects in the flow of the common carotid artery. The flow pattern of this artery in the elderly seemed plateau-like in the systolic forward flow phase (Fig. 4). Such a phenomenon had been noted and interpreted as related to cerebral arteriosclerosis by Kaneko et al. (1970). Namely, in the elderly, the flow pattern of the common carotid artery usually seemed less oscillatory, while those of the other arteries seemed more oscillatory, as mentioned above (Hayashi et al., 197I). Such a difference between the common carotid artery and the arteries in the extremities may be caused by differences in the distribution of elasticity, resistance, and so forth, between the two arterial trees. Much remains to be studied about such problems in the future.

The authors wish to thank Dr. M. Miyazaki, Kohsaiin Hospital, for the referral of volunteers for this study. 


\section{References}

Anliker, M., and Rockwell, R. L. (1971). Nonlinear analysis of flow pulses and shock waves in arteries. Part I: derivation and properties of mathematical model. Zamp, 22, 217.

Balas, P., Segditsas, T., and Koutsopoulos, D. (1970). The value of the ultrasonic flowmeter in the diagnosis of arterial diseases. Angiology, 21, $45 \mathrm{I}$.

Benchimol, A., Barreto, E. C., and Teng Wei Tio, S. (1970). Phasic aortic flow velocity in patients with pulsus alternans. British Heart fournal, 32, 696.

Benchimol, A., and Desser, K. B. (1972). Clinical application of the Doppler ultrasonic flowmeter. American fournal of Cardiology, 29, 540.

Benchimol, A., Desser, K. B., and Gartlan, J. L., Jr. (1972). Bidirectional blood flow velocity in the cardiac chambers and great vessels studied with the Doppler ultrasonic flowmeter. American fournal of Medicine, 52, 467.

Benchimol, A., Maia, I. G., Gartland, J. L., Jr., and Franklin, D. (1968). Telemetry of arterial flow in man with a Doppler ultrasonic flowmeter. American fournal of Cardiology, 22, 75.

Cross, G., and Light, L. H. (I971). Direction-resolving Doppler instrument with improved rejection of tissue artifacts for transcutaneous aortovelography. Fournal of Physiology, 217, 5P.

Evans, D. S., and Cockett, F. B. (1969). Diagnosis of deepvein thrombosis with an ultrasonic Doppler technique. British Medical fournal, 2, 802.

Franklin, D. L., Schlegel, W., and Rushmer, R. F. (196I). Blood flow measured by Doppler frequency shift of backscattered ultrasound. Science, 134, 564.

Hale, J. F., McDonald, D. A., and Womersley, J. R. (1955). Velocity profiles of oscillating arterial flow, with some calculations of viscous drag and the Reynolds number. fournal of Physiology, 128, 629.

Hayashi, T., Nimura, Y., Takahashi, Y., Abe, H., Matsuo, H., and Kitabatake, A. (I97I). Analysis of reverse phase in arterial flow in situ with directional ultrasonic Doppler method. Paper read at the Irth Annual Meeting of the Japanese College of Angiology, Maebashi (in Japanese).

Joyner, C. R., Jr., Harrison, F. S., Jr., and Gruber, J. W. (I97I). Diagnosis of hypertrophic subaortic stenosis with a Doppler velocity flow detector. Annals of Internal Medicine, 74, 692.

Kalmanson, D., Veyrat, C., Derai, C., Savier, C. H., Berkman, M., and Chiche, P. (1972). Non-invasive technique for diagnosing atrial septal defect and assessing shunt volume using directional Doppler ultrasound. Correlations with phasic flow velocity patterns of the shunt. British Heart fournal, 34, 98I.

Kaneko, Z., Kotani, H., Komuta, K., and Satomura, S. (196I). Studies on peripheral circulation by 'ultrasonic blood rheograph'. Fapanese Circulation fournal, 25, 203.

Kaneko, Z., Shiraishi, J., and Omizo, H. (1968). Analysis of ultrasonic blood rheogram by a band pass filter. Angio$\log y$, 19, 10.

Kaneko, Z., Shiraishi, J., Omizo, H., Inaoka, H., and Ueshima, T. (1970). Analysis of ultrasonic blood rheogram by the sound spectrograph. Fapanese Circulation fournal, 34, 1035 .

Kaneko, Z., Shiraishi, J., Omizo, H., Kato, K., Motomiya, M., Izumi, T., and Okumura, T. (1965). An analyzing method of ultrasonic blood-rheograph with sonagraph. Digest of the 6th International Conference on Medical Electronics and Biological Engineering, Tokyo, p. 286.

Kato, K. (1966). Ultrasonic diagnostic instruments. In Ultrasonics in Medicine - Principle, Research and Practice, p. 138. Ed. by the Japan Society of Ultrasonics in Medicine. Igaku Shoin, Tokyo. (In Japanese.)
Kato, K., and Izumi, T. (1966). On a method of indication of reverse flow in the ultrasonic Doppler flowmeter. In Proceedings of the roth Meeting of the Japan Society of Ultrasonics in Medicine, p. 78. (In Japanese.)

Kato, K., and Izumi, T. (1967). A new ultrasonic Doppler flowmeter that can defect flow direction. Medical Ultrasonics, $5,28$.

Kato, K., Kakusho, O., and Izumi, T. (1968). A new ultrasonic Doppler Howmeter that can detect flow direction. Paper read in the 6th International Congress of Acoustics, Tokyo.

Kato, K., Kido, Y., Motomiya, M., Kaneko, Z., and Kotani, H. (I962). On the mechanism of generation of detected sound in ultrasonic flow meter. Memoirs of the Institute of Scientific and Industrial Research, Osaka University, 19, 51 .

Kobayashi, Y. (I97I). Studies on clinical application of ultrasonic Doppler technique for several circulatory diseases. Nagoya Medical fournal, 93, 368. (In Japanese.)

Lee, B. Y., Castillo, H. T., and Madden, J. L. (1970). Quantification of the arterial pulsatile blood flow waveform in peripheral vascular disease. Angiology, 21, 595.

Light, L. H. (1970). A recording spectrograph for analysing Doppler blood velocity signals (particularly from aortic flow) in real time. Fournal of Physiology, 207, 42P.

Light, L. H. (197I). Direction-resolving Doppler system and real-time spectrographic recorder for transcutaneous aortovelography. Digest of 9 th International Conference on Medical Electronics and Biological Engineering. Melbourne, p. 228.

Light, L. H., and Cross, G. (1972). Cardiovascular data by transcutaneous aortovelography. In Blood Flow Measurement, p. 6o. Ed. by C. Roberts. Sector Publishing, London.

McLeod, F. D. (1967). A directional Doppler flowmeter. Digest of the 7 th International Conference on Medical and Biological Engineering. Stockholm, p. 213.

Miyazaki, M. (1965). Measurement of cerebral blood flow by ultrasonic Doppler technique. Fapanese Circulation fournal, 29, 375 .

Mizuno, S. (1969). Experimental and clinical studies on clinical application of ultrasonic Doppler rheograph. Nagoya Medical fournal, 92, 293. (In Japanese.)

Pourcelot, L. (I97I). Nouveau débitmetre sanguin à effet Doppler. Ultrasonographic Medica I, 125, Verlag der Wiener Medizinischen Akademie, Vienna.

Reid, J. M., Sigelman, R. A., and Nasser, M. G. (1969). The scattering of ultrasound by human blood. Proceedings of the 8th International Conference on Medical Electronics and Biological Engineering, paper 10-7, Chicago.

Rushmer, R. F., Baker, D. W., and Stegall, H. F. (1966). Transcutaneous Doppler flow detection as a nondestructive technique. Fournal of Applied Physiology, 21, 554.

Sakamoto, T., Saito, M., and Nakayma, K. (1966). Analysis of motion of viscous liquid in a thin-walled elastic tube. Fapanese fournal of Medical Electronics and Biological Engineering, 4, 408. (In Japanese.)

Satomura, S. (1957). Ultrasonic Doppler method for the inspection of cardiac function. Fournal of the Acoustical Society of America, 29, 1181 .

Satomura, S. (1959). Study of the flow patterns in peripheral arteries by ultrasonics. Nippon Onkyo Gakkai-shi (fournal of the Acoustical Society of fapan), 15, 151. (In Japanese.)

Satomura, S., and Kaneko, Z. (I960). Ultrasonic blood rheograph. Proceedings of the 3 rd International Conference on Medical Electronics. London, p. 254.

Satomura, S., Matsubara, S., and Yoshioka, M. (1956). A new method of mechanical vibration measurement and its application. Memoirs of the Institute of Scientific and Industrial Research, Osaka University, 13, 125. 
Strandness, D. E., Jr., Kennedy, J. W., Judge, T. P., and McLeod, F. D. (1969). Transcutaneous directional flow detection. A preliminary report. American Heart fournal, 78,65 .

Strandness, D. E., Jr., McCutcheon, E. P., and Rushmer, R. F. (1966). Application of a transcutaneous Doppler flowmeter in evaluation of occlusive arterial disease. Surgery, Gynecology and Obstetrics, 122, 1039.

Strandness, D. E., Jr., Schultz, R. D., Sumner, D. S., and Rushmer, R. F. (1967). Ultrasonic flow detection. A useful technic in the evaluation of peripheral vascular disease. American fournal of Surgery, II3, $31 \mathrm{I}$.
Womersley, J. R. (I955). Method for the calculation of velocity, rate of flow and viscous drag in arteries when the pressure gradient is known. Fournal of Physiology, 127, 553.

Yao, S. T., Hobbs, J. T., and Irvine, W. T. (I968). Pulse examination by an ultransonic method. British Medical fournal, 4, 555 .

Requests for reprints to Dr. Yasuharu Nimura, the First Department of Medicine, Osaka University Medical School, Dojima-Hamadori 3-chome, Fukushima-ku, Osaka, 553 Japan. 